\title{
Diagnostic Accuracy of Computed Tomography in Detecting Bone Invasion due to Squamous Cell Carcinoma of Buccal Mucosa
}

\author{
Nasreen Naz1, Javeriya Sattar1 and S. Khalid Ashrafi2
}

\begin{abstract}
Objective: To determine the diagnostic accuracy of contrast enhanced computed tomography (CECT) of head and neck in detecting adjacent bone invasion due to squamous cell carcinoma of buccal mucosa using histopathology as gold standard.

Study Design: Cross sectional / descriptive study.

Place and Duration of Study: Department of Radiology, Dow Medical College, Civil Hospital, Karachi, from September 2015 to October 2016.

Methodology: A total of 116 patients clinically suspected of oral cavity squamous cell carcinoma (OCSCC) involving buccal mucosa was included. After taking proper history, all these patients referred to Radiology Department for contrast enhanced contiguous thin slice sections of 3-5 mm the primary site of the lesion prior to surgery. Reconstruction of all images done by using bone algorithm. The diagnostic accuracy of CECT was analysed against the gold standard of histopathology. Statistical analyses were carried out by using SPSS 21. Mean \pm SD were calculated for quantitative variable like age. For qualitative variables, frequencies and percentages were calculated. Sensitivity, specificity, positive predictive value, negative predictive value, and diagnostic accuracy were computed for CECT, taking histopathology as gold standard.

Results: Eighty-three male $(71 \%)$ and 33 female $(28 \%)$ patients. Mean age was $46.66 \pm 10.77$ years. Mean duration of sign and symptoms was $3.47 \pm 1.54$ months. Sensitivity, specificity, PPV, NPV and accuracy were $69.2 \%, 78.4 \%$, and $80.4 \%$, $66.7 \%$ and $73.3 \%$, respectively.

Conclusion: CECT is a reliable technique for detecting adjacent bone invasion due to squamous cell carcinoma of buccal mucosa by using 3-5 $\mathrm{mm}$ thin-section CT reconstructed with bone algorithm.
\end{abstract}

Key Words: Bone invasion, Buccal mucosa, Contrast enhanced computed tomography, Diagnostic accuracy, Histopathology, OCSCC, Squamous cell carcinoma.

\section{INTRODUCTION}

Oral cancer is a violent, ${ }^{1}$ and devastating disease, which ranks second commonest malignancy in Pakistan. (Incidence rate, according to age standardised rates in the world, is 5.3 in males and 2.6 in females). Oral cancer is the great risk to public health of not only in Pakistan but all over the world, although a wide geographical variation noted in the occurrence and outcomes. ${ }^{2}$

According to recent cancer registry record of Shaukat Khanum Memorial Hospital, Lahore, it is the eighth most common worldwide malignancy; but in the Pakistan, it is the second commonest malgnancy. It accounts for $15 \%$ of all new cancer cases in this region in comparison to $3 \%$ detected worldwide. ${ }^{2}$

\footnotetext{
1 Department of Radiology, Dow Medical College (DMC), Civil Hospital, Karachi, Pakistan

2 Department of ENT, Abbasi Shaheed Hospital, Karachi, Pakistan

Correspondence: Dr. Nasreen Naz, Department of Radiology, Dow Medical College (DMC), Civil Hospital, Karachi,

Pakistan

E-mail: nasreenradiologist@gmail.com

Received: January 27, 2018; Accepted: May 21, 2018
}

The prevalence of oral cancer is variable throughout the world. It is higher in Pakistan reaching the $10 \%$ of all cancers, and around $45 \%$ in India. A study conducted in Pakistan during 1995-2004 showed much higher incidence rate, $22.5 \%$ in males and $20.4 \%$ in females. ${ }^{3}$ Over 300,000 new cases of oral and oropharyngeal cancer were diagnosed in 2004-2009 worldwide, and over 7,000 affected individuals died of these cancers. ${ }^{4}$

It is estimated that more than $90 \%$ of all oral neoplasms are oral squamous cell carcinoma (OSCC), so this term tends to be used interchangeably with oral cancer. ${ }^{4}$

Squamous cell carcinoma (SCC) comprises $90 \%$ of head and neck cancers; whereas, oral cavity squamous cell carcinoma (OCSCC) is the commonest. Subsites of oral cavity are lip, alveolar ridge, buccal mucosa, retromolar trigone, floor of mouth and tongue; 5 but buccal mucosa being the aggressive subsite. ${ }^{6}$ Risk factors associated with SCC include betel quid chewing, tobacco and alcohol consumption. ${ }^{7}$

Although there are rapid advancements in the diagnostic and therapeutic procedures in the past decades, but the five-year survival rate has showed none or only slight improvement at $65 \%$ between $2002-2008.5$

If disease is properly diagnosed and staging done at early phase, then treatment option is surgical (transoral 
wide excision 1) followed by radiotherapy, which improves survival rate. For advanced lesions with local invasion, elective neck dissection combined with postoperative radiation is indicated. 7

So, it is very important to identify local bony invasion precisely. Pattern of bony invasion of maxilla and mandible is a pivot for distinguishing $T$ stage and further management. 8

Pre-treatment CECT is one of the valuable techniques in staging of the disease, evaluation of adjacent osseous invasion and it also detects presence of cervical nodal metastasis that helps in treatment planning and posttreatment follow-up of patients with head and neck cancer, ${ }^{9}$ along with histopathology of the lesion. To design an effective treatment strategy, two tasks are very important; accurate staging and timely assessment of the cancer ${ }^{9}$, which is not possible without CECT.

The aim of this study was to determine the diagnostic accuracy of CECT in preoperative detection of local bone invasion by comparing its findings with histopathology. This would prevent unnecessary extensive surgical excision, which will considerably decrease morbidity in patients.

\section{METHODOLOGY}

This study was conducted at the Department of Radiology, Civil Hospital, Karachi, from September 2015 to September 2016. Consecutive patients who were referred to Radiology Department, Civil Hospital, Karachi for CECT of head and neck, presenting with clinically diagnosed cases of the oral cavity carcinoma and had less than or equal to 6 months duration, were included in the study. Suspected lesions are lump or thickening of oral soft tissues, painless mouth ulcers that do not heal within 6 weeks, clinically obvious potentially malignant disorders (PMDs) like leukoplakia (white patch), and indurated lumps or ulcers (infiltrated beneath the mucosa) or a lesion which was fixed to deeper tissues. Only preoperative patients 18 to 65 years of either gender were selected. Patients with history of previous allergic reactions to contrast dental implants, post-surgical cases for oral cancers or post radiotherapy/chemotherapy and with recurrence of oral cancers were excluded from the study.

All those patients who were referred to Radiology Department for CECT of head and neck, fulfilling the inclusion criteria, were selected, after taking informed consent from the patients explaining the utility of the study for their further management and explaining the radiation hazards and possibility of contrast reactions. The procedures were performed by using Toshiba Activation 16 slice multidetector CT scanner with imaging protocol of axial, sagittal, and coronal studies with 3-5 $\mathrm{mm}$ contiguous sections with reconstruction, using bone and soft tissue algorithm, at Civil Hospital,
Karachi. Visualisation of absent bone invasion on CECT was control the effect modification. The features of bone invasion were carefully evaluated by the consultant radiologist having five years or more experience in computed tomography reporting, assisted by the investigator. The investigation was performed free of cost and these imaging features were then compared with histopathology after biopsy or surgery. The diagnostic accuracy of CECT was analysed against the gold standard of histopathology. Statistical analyses were carried out by using SPSS 21. Mean \pm SD were calculated for quantitative variable like age. For qualitative variables, frequencies and percentages were calculated. Sensitivity, specificity, positive predictive value, negative predictive value, and diagnostic accuracy were computed for CECT taking histopathology as gold standard. The stratification, according to gender, age and duration of sign and symptoms, was done and sensitivity, specificity, and diagnostic accuracy were also calculated. Post- stratification with these modifiers was calculated using Chi-square test considering $\mathrm{p}$-value $\leq 0.05$ as significant.

\section{RESULTS}

Out of 116 study subjects, $83(71 \%)$ were males and $33(28 \%)$ were females. Frequency of gender distribution is depicted in Table I.

The total mean age was $46.66 \pm 10.77$ years. The overall age is presented in Figure 1.

Sensitivity, specificity, predictive values and diagnostic accuracy of CECT for the detection of head and neck adjacent bone invasion due to squamous cell carcinoma

Table I: Characteristics of study population.

\begin{tabular}{lc}
\hline Variables & $\mathrm{n}(\%)$ \\
\hline Age groups & \\
$\leq 45$ years & $55(47 \%)$ \\
$>45$ years & $61(53 \%)$ \\
Mean \pm SD & $46.66 \pm 10.77$ \\
\hline Duration of symptoms & \\
1-3 months & $59(50.9 \%)$ \\
$4-6$ months & $57(49.1 \%)$ \\
Mean \pm SD & $3.47 \pm 1.54$ \\
\hline Gender & \\
Male & $83(72 \%)$ \\
Female & $33(28 \%)$ \\
\hline
\end{tabular}

Table II: Diagnostic accuracy of CT scan for adjacent bone invasion $(n=116)$

\begin{tabular}{l|c|c|c|c}
\hline \multirow{2}{*}{ CT Scan } & \multicolumn{3}{|c|}{ Histopathology } & \multirow{2}{*}{ Value } \\
\cline { 2 - 4 } & $\begin{array}{c}\text { Present } \\
(\mathrm{n}=65)\end{array}$ & $\begin{array}{c}\text { Absent } \\
(\mathrm{n}=51)\end{array}$ & Total & \\
\hline Present $(\mathrm{n}=56)$ & 45 & 11 & 56 & $<0.000^{*}$ \\
Absent $(\mathrm{n}=60)$ & 20 & 40 & 60 & \\
Total & 65 & 51 & 116 & \\
\hline Sensitivity & Specificity & PPV & NPV & Accuracy \\
$69.2 \%$ & $78.4 \%$ & $80.4 \%$ & $66.7 \%$ & $73.3 \%$ \\
\hline
\end{tabular}


Table III: Effect of other variables on diagnostic accuracy of CT scan for adjacent bone invasion.

\begin{tabular}{|c|c|c|c|c|c|}
\hline \multirow[t]{2}{*}{ Variables } & \multirow[t]{2}{*}{ CT scan } & \multicolumn{2}{|c|}{ Histopathology } & \multirow[t]{2}{*}{$\mathrm{P}$-value } & \multirow[t]{2}{*}{ Statistics } \\
\hline & & Present & Absent & & \\
\hline \multicolumn{6}{|l|}{ Age groups } \\
\hline \multirow[t]{2}{*}{$\leq 45$ years } & Present & 28 & 2 & $0.00^{\star}$ & $S n=82.35 \%, S p=90.47 \%$ \\
\hline & Absent & 6 & 19 & & $\begin{array}{l}\mathrm{PPV}=93.33 \%, \mathrm{NPV}=76 \% \\
\mathrm{DA}=85.45 \%\end{array}$ \\
\hline \multirow[t]{2}{*}{$>45$ years } & Present & 17 & 9 & $0.04^{*}$ & $S n=54.83 \%, S p=70 \%$ \\
\hline & Absent & 14 & 21 & & $\begin{array}{l}P P V=65.38 \%, N P V=60 \% \\
D A=62.29 \%\end{array}$ \\
\hline \multicolumn{6}{|l|}{ Gender } \\
\hline \multirow[t]{2}{*}{ Female } & Present & 13 & 4 & $0.027^{*}$ & $S n=68.42 \%, S p=71.42 \%$ \\
\hline & Absent & 6 & 10 & & $\begin{array}{l}\mathrm{PPV}=76.47 \%, \mathrm{NPV}=62.5 \% \\
\mathrm{DA}=69.69 \%\end{array}$ \\
\hline \multirow[t]{2}{*}{ Male } & Present & 32 & 7 & $0.00^{*}$ & $S n=69.57 \%, S p=81.08 \%$ \\
\hline & Absent & 14 & 30 & & $\begin{array}{l}P P V=82.05 \%, N P V=68.18 \%, \\
D A=74.7 \%\end{array}$ \\
\hline \multicolumn{6}{|c|}{ Duration of symptoms } \\
\hline \multirow[t]{2}{*}{ 1-3 months } & Present & 16 & 6 & $0.001^{*}$ & $S n=61.53 \%, S p=81.81 \%$ \\
\hline & Absent & 10 & 27 & & $\begin{array}{l}\mathrm{PPV}=72.72 \%, \mathrm{NPV}=72.97 \%, \\
\mathrm{DA}=72.88 \%\end{array}$ \\
\hline \multirow[t]{3}{*}{ 4-6 months } & Present & 29 & 5 & $0.00^{*}$ & $S n=74.35 \%, S p=72.22 \%$ \\
\hline & Absent & 10 & 13 & & $P P V=85.29 \%, N P V=56.52 \%$ \\
\hline & & & & & $\mathrm{DA}=73.68 \%$ \\
\hline
\end{tabular}

Sn = Sensitivity $; \quad S p=$ Specificity $; \quad P P V=$ Positive predictive value; NPV = Negative predictive value; $D A=$ Diagnostic accuracy.

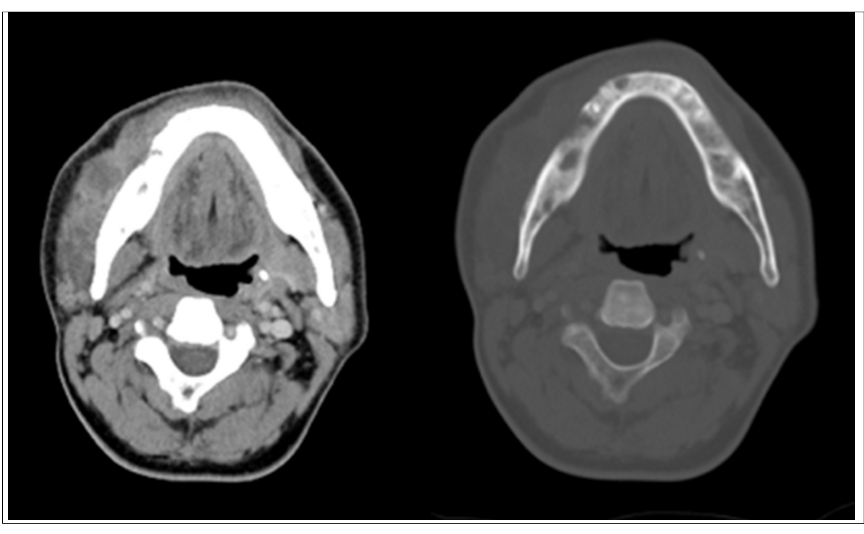

Figure 1: True positive case of right buccoalveolar carcinoma in 55-year male (a) Axial CECT, soft tissue window right sided soft tissue mass with loss of buccoalveolar sulcus (b) Axial CECT image (bone window) shows cortical erosion along the right buccal aspect of the mandibular alveolus. Findings were histologically confirmed, right buccoalveolar carcinoma with adjacent cortical erosion.

of buccal mucosa taking histopathology as gold standard, were calculated.

The results showed that 45 patients were true positive, correctly diagnosed with bone invasions, Figure 1. Forty patients were true negative, correctly diagnosed that there is no bone invasion/erosion. Sensitivity, specificity, PPV, NPV and accuracy were $69.2 \%, 78.4 \%, 80.4 \%$, $66.7 \%$ and $73.3 \%$, respectively. These results are depicted in Tables II and III.

\section{DISCUSSION}

Oral carcinoma is a devastating and fatal disease with increasing incidence, poor outcome and constantly low survival rate for the last three decades. Although a wide geographical variation in incidence and mortality is observed, it has raised great concern all over the world and is a major threat to public health in Pakistan. ${ }^{2}$

Almost $90 \%$ of all oral cancers are caused by tobacco. ${ }^{9}$ Cigarettes are the most common of the various forms of smoked tobacco. There are certain genotoxic substances which are called betel quid substitutes (BQS), found in gutka and pan masala etc. These have great carcinogenic effects. In tobacco, the main carcinogenic component is nitrosamines. ${ }^{10}$

Resection of the mandible is quite a challenging issue among the functional and reconstructive problems. Therefore, proper clinical and radiological evaluation is required prior to surgery. It is further noted that preoperative assessment of bone invasion by tumors of the oral cavity provides important information to the head and neck surgeon. Clinical assessment of mandibular invasion is performed by bimanually assessing the mobility of the tumor mass in relation to the mandible. However, CECT is proven to be an important diagnostic tool for evaluating patients with squamous cell carcinoma of the oral cavity. CT is readily available and offers faster image acquisition. ${ }^{11}$ CT serves as a first line investigation to broadly distinguish pathological processes. CECT may provide information regarding adjacent bone invasion, staging of the primary site and lymph nodes involvement. 12,13

The results of this study is comparable, favourably with those of Close et al. ${ }^{14}$ and are superior to more recent studies that have cast doubt on the ability of CT to accurately predict involvement of the mandible by squamous cell carcinoma of the oral cavity. ${ }^{15}$ 
Brown et al. ${ }^{16}$ (false-positive rate=28\%) and Curran et al..$^{17}$ (specificity $=57 \%$; positive predictive value $=73 \%$ ) acquired their images using 4- to 5-mm-thick sections and did not routinely evaluate the bone with bone algorithms. Shaha, (diagnostic accuracy $=68 \%$ ) and Bahadur, (false-negative rate $=28 \%$ ) did not describe their CT techniques. 18,19 Lane et al. obtained 5-mm-thick sections and did not reconstruct the studies in bone algorithm when evaluating for bone invasion. ${ }^{15}$ Close et al. obtained 5-mm-thick contiguous sections. ${ }^{14}$

In this study, sensitivity, specificity, PPV, NPV and diagnostic accuracy is $69.2 \%, 78.4 \%, 80.4 \%, 66.7 \%$ and $73.3 \%$, respectively. This is comparable to Suresh et al. which has sensitivity, $96 \%$; specificity, $87 \%$; positive predictive value, $89 \%$; and negative predictive value, $95 \% .20$ Hence, the higher specificity and positive predictive value of CT suggest that properly performed CT with bone algorithm and thin $3 \mathrm{~mm}$ slices are superior. 21

The present results, along with the current literature, make it clear that a high-quality imaging technique is necessary for CT to be used as a reliable modality for detecting bone invasion. Additionally, it is believed that the slice thickness should not exceed $3 \mathrm{~mm}$ and there should be reconstructed images, using bone algorithm. Moreover, volumetric acquisition can be used to improve the diagnostic accuracy for detecting bone invasion. It is possible that data obtained at 3-mm-thick slices reconstructed at 1 - to 2-mm intervals may improve the ability of CT to detect bony invasion. Helical acquisition using new multidetector CT units now permits even faster acquisition of studies performed with thin sections (contiguous 1-2 mm) over a large area.22 The potential for improving diagnostic accuracy using these new techniques warrants future investigation; and findings were histologically confirmed.

The sample size was small, the study was confined to a single centre, and study targeted only local subjects, so it is not clear whether our findings could be generalised nationally and internationally. A further drawback is that male gender predominated in our survey and the study was conducted on urban environment.

Limited research has been carried out in this perspective in Pakistan; however, incidence of OCSCC is very high.

\section{CONCLUSION}

The study results showed that sensitivity, specificity, and diagnostic accuracy were $69.2 \%, 78.4 \%$, and $73.2 \%$, respectively. The results of our investigation show that CECT, using thin slice $3-5 \mathrm{~mm}$ sections along bone reconstructed algorithm, is a reliable technique for detecting adjacent bone invasion due to squamous cell carcinoma of buccal mucosa.

\section{REFERENCES}

1. Bachar G, Goldstein DP, Barker E, Lea J, O'Sullivan B, Brown DH, et al. Squamous cell carcinoma of the buccal mucosa: outcomes of treatment in the modern era. Laryngoscope 2012; 122:1552-7.

2. Akram S, Mirza T, Mirza MA, Qureshi M. Emerging patterns in clinico-pathological spectrum of oral cancers. Pak J Med Sci 2013; 29:783.

3. Bhurgri Y, Bhurgri A, Nishter S, Ahmed A, Usman A, Pervez S, et al. Pakistan-country profile of cancer and cancer control 1995-2004. J Pak Med Assoc 2006; 56:124-30.

4. Markopoulos AK. Current aspects on oral squamous cell carcinoma. Open Dent J 2012; 6:126-30.

5. Belcher R, Hayes K, Fedewa S, Chen AY. Current treatment of head and neck squamous cell cancer. J Surg Oncol 2014; 110:551-74

6. Lubek JE, Dyalram D, Perera EH, Liu X, Ord RA. A retrospective analysis of squamous carcinoma of the buccal mucosa: an aggressive subsite within the oral cavity. $J$ Oral Maxillofac Surg 2013; 71:1126-31.

7. Fang QG, Shi S, Li ZN, Zhang X, Liua FY, Xu ZF, et al. Squamous cell carcinoma of the buccal mucosa: analysis of clinical presentation, outcome and prognostic factors. Mol Clin Oncol 2013; 1:531-4.

8. Hakim SG, Wieker H, Trenkle T, Sieg P, Konitzer J, Holl-Ulrich K, et al. Imaging of mandible invasion by oral squamous cell carcinoma using computed tomography, cone-beam computed tomography and bone scintigraphy with SPECT. Clin Oral Investig 2014; 18:961-7.

9. Singh D, Sahoo S, Gupta V, Srivastava D. Latest advancements in imaging of oral and maxillofacial neoplasm: A comprehensive review. J Oral Maxillofac Radiol 2013; 1:37.

10. Shah S, Merchant A, Luby S, Chotani R. Addicted schoolchildren: Prevalence and characteristics of areca nut chewers among primary school children in Karachi, Pakistan. $J$ Paediatr Child Health 2002; 38:507-10.

11. Iqbal J, Rashid S, Fatima S, Murtaza S, Darira J, Ahmed MS. Determine the diagnostic accuracy of multislice computed tomography in detecting squamous cell carcinoma of oral cavity taking histopathology findings as gold standard. Pak $J$ Radiol 2007; 27:30-5.

12. Som PM. Lymph nodes of the neck. Radiology 1987; 165 : 593-600.

13. Curtin HD, Ishwaran H, Mancuso AA, Dalley RW, Caudry DJ, McNeil BJ. Comparison of CT and MR imaging in staging of neck metastases. Radiology 1998; 207:123-30.

14. Close LG, Burns DK, Merkel M, Schaefer SD. Computed tomography in the assessment of mandibular invasion by intraoral carcinoma. Ann Otol Rhinol Laryngol 1986; 95:383-8.

15. Lane AP, Buckmire RA, Mukherji SK, Pillsbury III HC, Meredith SD. Use of computed tomography in the assessment of mandibular invasion in carcinoma of the retromolar trigone. Otolaryngol Head Neck Surg 2000; 122:673-7.

16. Bruening RD, Sturm C, Jaeger LJ, Schoepf UO, Becker MD, Reiser MF. Subsecond multiple detector CT improves imaging of the larynx. Radiology 1999; 213(suppl):278-9. 
17. Curran A, Toner M, Quinn A, Wilson G, Timon C. Mandibular invasion diagnosed by SPECT. Clin Otolaryngol Allied Sci 1996; 21:542-5.

18. Shaha AR. Preoperative evaluation of the mandible in patients with carcinoma of the floor of mouth. Head Neck 1991; 13: 398-402.

19. Bahadur S. Mandibular involvement in oral cancer. J Laryngol Otol 1990; 104:968-71.

20. Mukherji SK, Isaacs DL, Creager A, Shockley W, Weissler M, Armao D. CT detection of mandibular invasion by squamous cell carcinoma of the oral cavity. AJR Am J Roentgenol 2001; 177:237-43.

21. Chung TS, Yousem DM, Seigerman HM, Schlakman BN, Weinstein GS, Hayden RE. MR of mandibular invasion in patients with oral and oropharyngeal malignant neoplasms. Am J Neuroradiol 1994; 15:1949-55.

22. Uribe S, Rojas LA, Rosas CF. Accuracy of imaging methods for detection of bone tissue invasion in patients with oral squamous cell carcinoma. Dentomaxillofac Radiol 2013; 42: 20120346.

....杄.... 